\title{
Dose de soro (antiveneno) no tratamento do envenenamento por serpentes peçonhentas do gênero Bothrops
}

\author{
M.T. J ORGE, L.A. RIBEIRO \\ Departamento de Clínica Médica, Universidade Federal de U berlândia, U berlândia, MG.
}

UNITERMOS: Picada de cobra. Envenenamento. Soro antiofídico. Tratamento.

KEY Words: Snake bites. Poisoning. Antivenom. Treatment.

São notificados, anualmente, mais de 20.000 acidentes por serpentes peçonhentas no Brasil e mais de 2.000 somente no Estado de São Paulo. Bothrops (jararacas), Crotalus (cascavel), Lachesis (surucucu) e Micrurus (coral verdadeira) foram responsáveis por, respectivamente, $88,3 \%, 8,3 \%, 2,7 \%$ e $0,7 \%$ dos acidentes notificados no país, de junho de 1986 a dezembro de 1987, em que se fez referência ao gênero da serpente ${ }^{1,2}$. O tratamento específico desses envenenamentos é realizado com soro eqüino contra venenos de serpentes do mesmo gênero da que causou 0 acidente ${ }^{3-5}$. Exceto para Crotalus e para Lachesis, por só haver no Brasil uma espécie de cada ${ }^{6}$, soros antiofídicos específicos para cada espécie não são disponíveis no país ${ }^{3,5}$. As doses recomendadas foram, inicialmente, baseadas na estimativa da quantidade de veneno que a serpente poderia inocular e na capaci dade neutral izante do soro mensurada por soroneutralização in vitro e posterior inoculação em animais de experimentação ${ }^{7,8}$. Nas últimas décadas, baseou-se, também, em opiniões de médicos com experiência clínica não controlada ${ }^{3-5,9}$.

A quantidade de veneno que as serpentes inoculam durante o bote defensi vo é estimada pel o quanto se pode extrair de exemplares da mesma espécie $e^{7,8}$. U m erro, entretanto, pode advir do fato da quantidade de veneno que pode ser extraída pel o homem não ser necessariamente a mesma que a serpente consegue inocular. Após a estimativa da quantidade de veneno que pode ser inoculada, bastaria saber, para o tratamento do paciente, o volume de soro necessário para neutralizá-la ${ }^{8}$. Se a maior quantidade de veneno que se podia extrair, por exemplo, de Bothrops jararaca era cerca de 160mg, acreditava-se que um volume de soro suficiente para neutralizá-la seria suficiente para o tratamento de, virtualmente, todos os envenenamentos por essa serpente ${ }^{8}$. Nesse ponto, entretanto, o erro pode ser ainda maior. O doseamento do soro antibotrópico, por exemplo, é atualmente realizado por meio da soroneutralização, in vitro, de cinco doses letais 50\% (DL50) de veneno de $B$. jararaca incubadas com diferentes volumes do soro e posterior inoculação da solução, em camundongos, por via intraperitoneal ${ }^{10}$. Observando-se a sobrevida de $50 \%$ dos camundongos (DE50), pode-se avaliar o poder neutralizante do soro. A simples substituição do método Vital Brazil, que utiliza o pombo como animal de experimentação, para o método atual fez com que um mesmo soro antibotrópico passasse a ser consi derado como tendo o dobro da capacidade de neutralização ${ }^{11}$. Embora úteis, evidentemente, nenhuma dessas formas de doseamento corresponde à situação clínica em que o soro será utilizado. Embora não seja rotina a soroneutralização, pode, também, ser realizada in vivo, inoculando-se, separadamente, veneno e soro sem prévia neutralização, de forma mais parecida com o que acontece no tratamento clíni co $^{12,13}$. Também nessas condições, diferentes vias de inoculação do veneno e do soro ou diferentes períodos de tempo entre a administração de um e do outro podem acarretar resultados discrepantes.

A inoculação intramuscular do veneno de Bothrops ou de Crotalus, em camundongos, com posterior administração intraperitoneal de antiveneno, mostrou que, quando se administra o antiveneno 30 minutos após a inoculação do veneno, para se obter o mesmo efeito da sua administração concomitante, é necessário utilizar-se dose cerca de três vezes maior ${ }^{12,13}$. U ma dose de anticorpo (antiveneno) que, administrada imediatamente após a inoculação de uma certa quantidade do antígeno (veneno) é capaz de neutralizá-la totalmente, também deveria neutral izar todo o antígeno ainda di sponível, quando administrada trinta minutos após. Nesse caso, a triplicação da dose não deveria melhorar a resposta terapêutica. Pode ser, entretanto, que para se obter maior rapidez na neutralização haja necessidade de uma relação entre moléculas de anticorpos e de antígenos mais favorável ao primeiro. Sendo assim, a dose ideal de soro para o tratamento não seria aquel a capaz de neutral izar o veneno e, sim, a que o fizesse em curto espaço de tempo 
e seria, possivelmente, muito maior. $\mathrm{E} m$ todos esses métodos de doseamento do soro, o que se está avaliando é a sobrevida dos animais de experimentação e, portanto, a neutralização da fração do veneno que Ihes determina a morte. Essa fração, entretanto, pode não ser a mesma responsável pelo óbito no envenenamento humano.

Observa-se, pelo que foi dito, que a capacidade neutralizante do soro especificada na bula não representa um valor absoluto. Não se pode dizer, portanto, que um paciente que foi inoculado com 160mg de veneno de B. jararaca, necessariamente, terá tratamento adequado com soro na dose correspondente àquela que, segundo a bula do medicamento, neutralizaria tal quantidade de veneno. Há que se considerar, também, que a gravidade do envenenamento e, portanto, a dose necessária para o tratamento dependem de variáveis como: gênero, espécie e porte da serpente que causou o acidente, região anatômica picada, via de inoculação do veneno e do antiveneno, tempo transcorrido entre o aci dente e a sor oterapia, e outras ${ }^{4}$. I sso posto, podese concluir que, embora as várias formas utilizadas anteriormente possam ser úteis na avaliação da dose de antiveneno a ser administrada nos pacientes, essa deverá ser determinada, quando possível, por experimentos clínicos controlados. $\mathrm{Na}$ prática clínica, a orientação tem sido no sentido de se administrar o soro por via endovenosa, com a dose calculada por número de ampolas, de acordo com a gravidade do envenenamento e independente do peso do paciente $e^{3-5}$.

Devido à sua grande freqüência ${ }^{1} \mathrm{e}$, conseqüentemente, sua importância e a facilidade de se obter casos suficientes para os estudos, as primeiras avaliações das doses de soro necessárias para o tratamento foram feitas para o envenenamento botrópico.

Um estudo foi realizado em um momento muito especial, em que o Hospital Vital Brazil - Instituto Butantan (HVB-IB), especializado no atendimento de acidentes por animais peçonhentos, por motivo não relacionado a novos conhecimentos científicos, passou a utilizar doses menores de soro para o tratamento do envenenamento por Bothrops. F oram, então, comparados dois períodos (1983/84 e 1986), tendo sido utilizadas, no segundo, doses aproximadamente duas vezes menores do que no primeiro, não se observando diferença na freqüência de complicações relacionadas à picada ${ }^{14}$. Esse estudo, entretanto, não possibilitou avaliar sea utilização de soro em menor dose pode acarretar uma recuperação mais tardia da coagulação sanguínea ou um aumento da letal idade, pois o tempo gasto para a recuperação da coagulação não foi mensurado com precisão e, na região estudada, a serpente que mais comumente causa acidentes é $B$. jararaca, espécie que não tem sido causa freqüente de acidentes fatai $s^{15}$.

Dificuldades na produção dos soros antiofídicos e a utilização de doses cada vez maiores e que, eventualmente, poderiam ser excessivas estimularam a realização de estudos para avaliar as doses mais adequadas para o tratamento.

Em estudos recentes, o Butantan Institute Antivenom Study Group (BIASG) avaliou pacientes picados por serpentes do gênero Bothrops, nos quais administrou as doses de soro antibotrópico atualmente recomendadas pel os órgãos oficiais de saúde ${ }^{3,5}$ (4 ou 8 ampolas, respectivamente, para casos de envenenamento leve ou moderado) ${ }^{16}$. Observou-se que, após o tratamento, a maioria apresentou uma rápida melhora clínica e poucos desenvolveram novos sinais compatíveis com envenenamento. Através de imunoensaio enzimático (ELISA) foi possível observar que o veneno foi depurado do plasma de virtual mente todos os pacientes dentro de 4 dias e $o$ antiveneno permaneceu em concentrações relativamente altas nos três primeiros dias, decrescendo gradualmente nos 30 dias seguintes ${ }^{17}$. Concluiu-se que, provavelmente, ambos os grupos de pacientes receberam doses de antiveneno excessivas para neutralizar o veneno. Nos pacientes que receberam oito ampolas de antiveneno, entretanto, a queda dos níveis de antígenos foi mais rápida. Apesar da conclusão acima, não está absolutamente claro se, em casos excepcionalmente graves em que o paciente corre risco de vida por apresentar choque, sangramento grave, etc., não haveria benefício na administração de grandes quantidades de moléculas de anticorpos em relação à quantidade de antígeno inoculada.

Final mente, o BIASG realizou, também, um experimento clínico (randomizado e duplo-cego), em que 88 pacientes receberam tratamento com 4 ou 8 ampolas de soro de uso habitual, respectivamente para casos de envenenamento leve e moderado, e 82 foram tratados igual mente, porém receberam ampolas que apresentavam a metade da capacidade neutralizante (antiveneno diluído ao meio). Não se observaram diferenças nos resultados obtidos nos dois grupos quanto aos dados avaliados, ou seja, na normalização da coagulação sanguínea, nos níveis séricos de fibrinogênio e produtos da degradação da fibrina/ fibrinogênio e na freqüência de evolução para necrose e abscesso ${ }^{18}$.

Esses dados sugerem que as doses utilizadas para o tratamento do envenenamento por Bothrops no $H V B$, e que passaram a ser recomendadas pela Secretaria de Saúde do Estado de São Paulo $0^{5,9}$ e pelo Ministério da Saúde ${ }^{3}$, são desnecessariamente altas. 


\section{CONCLUSÃO}

Isto posto, pode-se dizer que a tendência atual deve ser a utilização de doses menores de soro, pelo menos quando se trata de envenenamentos leves e moderados, principalmente em locais de alta prevalência de B. jararaca. Envenenamentos graves não foram avaliados e permanecem as recomendações de doses altas (12 ou mais ampolas), conforme orientações oficiais ${ }^{3,5}$. Esses casos, entretanto, são menos freqüentes. Dada a diversidade de espécies encontradas nas várias regiões do país, é importante que estudos semelhantes sejam realizados também em outros locais, para se avaliar a eficácia dessas doses de antiveneno em relação a outras espécies peçonhentas.

\section{REFERÊNCIAS BIBLIOGRÁFICAS}

1. Ribeiro LA. Epidemiology of ophidic accidents. Mem Inst Butantan 1990; 52: 15-6.

2. Ribeiro LA, Pires de Campos VAF, Albuquerque MJ , Takaoka NY. E pidemi ol ogia do acidente ofídi co no Estado de São Paulo. Rev Ass Med Brasil 1993; 39: 4-7.

3. Brasil, Manual para o atendimento dos acidentes ofídicos. Ministérioda Saúde. CentrodeDocumentaçãodo Ministério da Saúde, 1991.

4. J orge MT, Ribeiro LA. Acidente por serpente peçonhenta do Brasil. Rev Ass Med Brasil 1990; 36: 66-77.

5. SãoPaulo, Manual devigilância epi demi ológica - Aci dentes por animais peçonhentos: identificação, diagnóstico e tratamento. Secretaria do Estado da Saúde, São Paulo, 1993.

6. Hoge AR, Romano-Hoge SARWL. Sinopse das serpentes peçonhentas do Brasil. Mem Inst Butantan 1978/79; 42/43: 373-499.

7. Belluomini HE. Estraction and quantities of venom obtained from some Braziliam snakes In Burcherl W, Buckley EE, Deul ofeu U. (eds): Venomous animals and their venoms. New York, Academic Press, 1988; 97-117.
8. Rosenfeld G. Symptomatology, pathology, and treatment of snakebite in South America. In Burcherl W, Buckley EE (eds): Venomous animals and their venoms. New York, Academic Press, 1971; 345-84.

9. São Paulo, Manual para o atendimento dos acidentes humanos por animais peçonhentos. Secretaria do Estado da Saúde, São Paulo, 1982.

10. Dalmora SL, Vaccari SF, SampedroAM, PereiraJ ES. Dosagem biológica do antiveneno botrópico. Mem Inst Butantan 1992; 54:21-30.

11. Zavareze C, Rocha CL. Estudo comparativo entre métodos utilizando pombos (DE edficaz 50\%) para determinação da potência de soros antibotrópicos. Rev Soc Bras Toxicol . 4 (supl. II) 1991; trabalho 81.

12. Agostini Utescher CL, Vieira SLP, Fensterseifer S, RibeiroLA, J orge MT. Avaliação da eficácia do antiveneno botrópico administrado no local da inoculação intramuscular do veneno de Bothrops jararaca: estudo experimental em camundongos. Rev Inst Med Trop São Paulo 1994; 36: 275-8.

13. Ribeiro LA, Agostini Utescher CL, Vieira SLP et al. Avaliação em camundongo da eficácia do antiveneno administrado no local da inoculação intramuscular do veneno de Crotalus durisssus terrificus. Rev Inst Med Trop São Paulo 1993; 35: 23-7.

14. J orge MT, Ribeiro LA. Efeito da redução na dose de soro antibotrópico administrada a pacientes picados por serpentes do gênero Bothrops. Rev Ass Med Brasil 1994; 40(1): 59-62.

15. Ribeiro LA, J orge MT. Epidemiologia e quadro clínico dos acidentes por serpentes Bothrops jararaca adultas e filhotes. Rev Inst Med Trop São Paulo 1990; 32: 436-42.

16. Cardoso J LC, Fan HW, França FOS et al. Randomized comparativetrial of threeantivenoms in thetreatment of envenoming by lance-headed vipers (Bothrops jararaca) in São Paulo, Brazil. Quat J Med 1993; 86: 315-25.

17. Theakston RDG, Fan HW, Warrell DA et al. Use of enzyme immunoassays to compare the effect and assess the dosage regimens of three Brasilian Bothrops antivenoms. Am J Trop Med Hyg 1992; 47: 593-604.

18. J orge MT, Cardoso J LC, Castro SCB et al. A randomized 'blinded' comparison of two doses of antivenom in the treatment of Bothrops envenoming in São Paulo, Brazil. Trans Soc Trop Med Hyg 1995; 89: 111-4. 